\title{
Erratum to: Clothing-Related Burn Casualties: An Overlooked Problem?
}

\author{
James F. Hoebel*, U.S. Consumer Product Safety Commission (Retired), \\ 13506 Star Flower Court, Chantilly, VA 20151, USA \\ Gordon H. Damant, Damant and Associates, 3550 Watt Avenue, Suite 5, \\ Sacramento, CA 95821, USA \\ Steven M. Spivak, Fire Protection Engineering, University of Maryland and \\ Stantex Consulting, 6301 Beachway Drive, Falls Church, VA 22044-1510, \\ USA \\ Geoffrey N. Berlin, 5330 Chelsen Wood Drive, Johns Creek, GA 30097, USA
}

\section{Erratum to: Fire Technol \\ DOI $10.1007 / \mathrm{s} 10694-009-0113-9$}

Unfortunately, first author James F. Hoebel's and co-author Gordon H. Damant's affiliations are erroneous in the original version.

Both authors departed from their organizations over a decade ago. The present language implies that the authors are currently affiliated with each organization. 